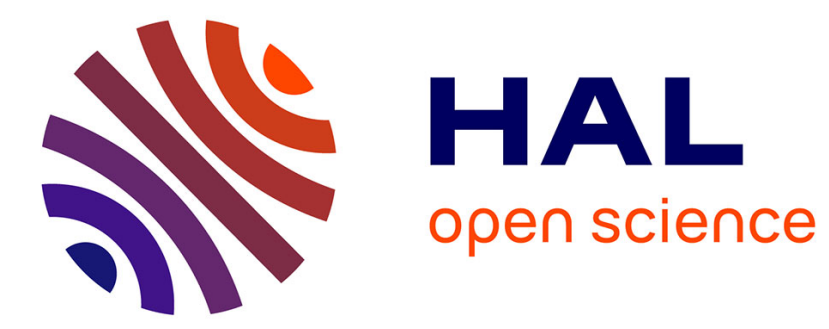

\title{
Temperature dependence of the Peierls gap in (TaSe4)2I
}

\author{
D. Berner, G. Scheiber, A. Gaymann, H. Geserich, P. Monceau, F. Lévy
}

\section{To cite this version:}

D. Berner, G. Scheiber, A. Gaymann, H. Geserich, P. Monceau, et al.. Temperature dependence of the Peierls gap in (TaSe4)2I. Journal de Physique IV Proceedings, 1993, 03 (C2), pp.C2-255-C2-258. 10.1051/jp4:1993251 . jpa-00251334

\section{HAL Id: jpa-00251334 https://hal.science/jpa-00251334}

Submitted on 1 Jan 1993

HAL is a multi-disciplinary open access archive for the deposit and dissemination of scientific research documents, whether they are published or not. The documents may come from teaching and research institutions in France or abroad, or from public or private research centers.
L'archive ouverte pluridisciplinaire HAL, est destinée au dépôt et à la diffusion de documents scientifiques de niveau recherche, publiés ou non, émanant des établissements d'enseignement et de recherche français ou étrangers, des laboratoires publics ou privés. 


\title{
Temperature dependence of the Peierls gap in $\left(\mathrm{TaSe}_{4}\right)_{2} I$
}

\author{
D. BERNER, G. SCHEIBER, A. GAYMANN, H.M. GESERICH, P. MONCEAU* and F. LÉVY** \\ Institut für Angewandte Physik, Universität Karlsruhe, Kaiserstr. 12, 76131 Karlsruhe, Germany \\ * Centre de Recherches sur les Très Basses Températures, CNRS, BP. 166X, 38042 Grenoble cedex, France \\ ** Institut de Physique Appliquée, EPF de Lausanne, PHB Ecublens, 1015 Lausanne, Switzerland
}

\begin{abstract}
We have determined the longitudinal optical conductivity of $\left(\mathrm{TaSe}_{4}\right)_{2} \mathrm{I}$ in the energy range from $50 \mathrm{meV}$ to $2 \mathrm{eV}$ at different temperatures between $15 \mathrm{~K}$ and $420 \mathrm{~K}$. We find a clear evidence that the free carriers are condensed into a charge density wave ground state not only below the transition temperature of $263 \mathrm{~K}$ but also at higher temperature up to the limits of the chemical stability of this compound.
\end{abstract}

\section{Introduction}

As the one-dimensional metallic state is instable against lattice distortions the chain-like compound $\left(\mathrm{TaSe}_{4}\right)_{2} \mathrm{I}$ undergoes a metal-insulator transition of Peierls type. This transition is associated with the appearence of an energy gap at the Fermi level and with the formation of charge density waves. Whereas the interesting non-linear transport properties of this material occurring below the transition temperature of $T_{p}=263 \mathrm{~K}$ were analyzed in many publications [1] the change of the electronic structure of this material during this transition was much less investigated. Therefore, this transformation is not understood in detail. Diffraction experiments have shown the development of a three-dimensional superstructure below $263 \mathrm{~K}$, reflecting a static Peierls distortion associated with three-dimensional ordering $[2,3]$. Whereas the electronic transport properties below the transition temperature can be described in the framework of a charge density wave condensate, i.e. by collective phenomena, the transport properties above $263 \mathrm{~K}$ were attributed to metallic behaviour, i.e. to single electron excitations. Optical measurements at room temperature, however, have exhibited strong deviations of the reflectance spectra of $\left(\mathrm{TaSe}_{4}\right)_{2} \mathrm{I}$ from metallic behaviour at photon energies below the plasma edge [4]. Therefore, it seemed to be obvious to continue and to complete these earlier optical investigations by determining the polarized reflectance spectra of $\left(\mathrm{TaSe}_{4}\right)_{2} \mathrm{I}$ at different temperatures above and below the transition temperature.

\section{Experimental}

Single crystals of $\left(\mathrm{TaSe}_{4}\right)_{2} \mathrm{I}$ were grown by standard temperature-gradient furnace techniques. The size of the crystals was about $6 \times 1 \times 1 \mathrm{~mm}^{3}$. They showed well-reflecting surfaces. The reflection measurements at room temperature and at higher temperatures were performed at near-normal incidence with a single-beam spectrometer, designed for the investigation of small samples. The low-Temperature spectra were obtained, using a Fourier transform spectrometer Bruker IFS 113v, equipped with a continuous-flow cryostat. The direction of polarization was parallel or perpendicular to the chain axis, respectively. 


\section{Results and discussion}

Fig. 1 shows the polarized reflectance spectra of $\left(\mathrm{TaSe}_{4}\right)_{2} \mathrm{I}$ in the energy range between $50 \mathrm{meV}$ and 6 $\mathrm{eV}$. The strong optical and electrical anisotropy of this material is well reflected by the room temperature data. For the electric field perpendicular to the chain axis the reflectivity is nearly constant, like in a typical insulator. For the electric field parallel to the chain axis a steep edge of the reflectivity near $1 \mathrm{eV}$ is observed, at a first glance, similar to the plasma edge of a one-dimensional free-electron gas. At lower energy, however, the reflectance spectrum deviates significantly from the free-electron behaviour, represented by the dashed line. This deviation still remains even when the temperature of the crystals is increased close to the limits of chemical stability, well above the transition temperature of 263 $\mathrm{K}$. When the crystal is cooled down to $15 \mathrm{~K}$ this deviation increases remarkably. The spectral distributions of the longitudinal optical conductivity, following from a Kramers-Kronig transformation of the reflectance spectra, are plotted in Fig.2. These conductivity spectra demonstrate more clearly the

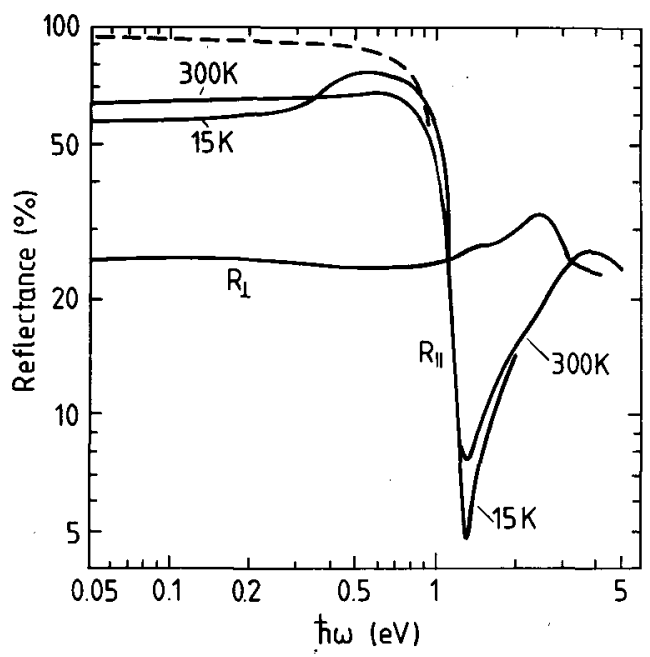

Fig.1 - Polarized reflectance spectra $R_{\|}$of $\left(\mathrm{TaSe}_{4}\right)_{2} \mathrm{I}$ in the metallic limit (dashed line), at $300 \mathrm{~K}$ and at $15 \mathrm{~K} ; R_{\perp}$ at $300 \mathrm{~K}$ (full lines).

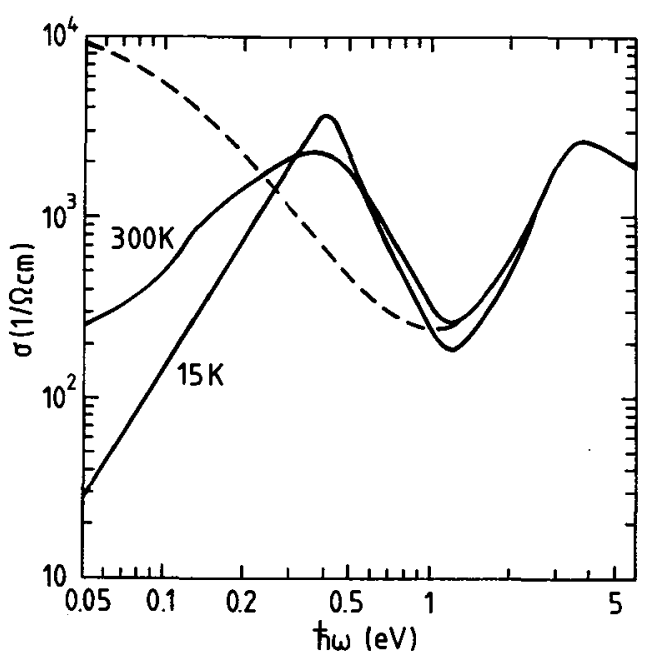

Fig.2 - Longitudinal optical conductivity calculated from the reflectance spectra of Fig.1.

significance of the deviation of the experimental spectra from the free-electron behaviour: Even at high temperatures, well above the transition temperature of $263 \mathrm{~K}$, no metallic state, i.e. no delocalized states at the Fermi level exist in $\left(\mathrm{TaSe}_{4}\right)_{2} \mathrm{I}$. Rather, a gap in the electronic excitation spectrum is present, mainifesting that even at high temperature the free carriers are condensed into a charge density wave groundstate. Above $263 \mathrm{~K}$, however, this charge density wave condensate shows no long-range order. It has the physical properties of a liquid. Therefore, the steep absorption edge, following from the joint density of states of a one-dimensional solid is smoothed out by tail states near the band edges. Below $263 \mathrm{~K}$ this "liquid" condensate crystallizes into a superlattice structure. Figs. 3 and 4 show a nearly continuous change of the optical spectra in the broad temperature range between $15 \mathrm{~K}$ and $300 \mathrm{~K}$. By continuous narrowing of the longitudinal conductivity spectrum the shape, determined by the onedimensional joint density of states, is approximated with decreasing temperature. Simultaneously, the gap 


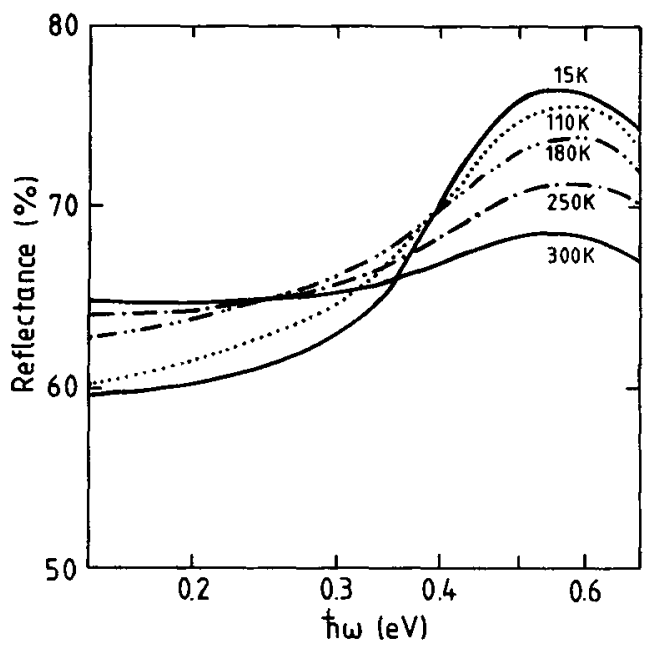

Fig.3 - Polarized reflectance spectra of $\left(\mathrm{TaSe}_{4}\right)_{2} \mathrm{I}$ at different temperatures (expanded scale)

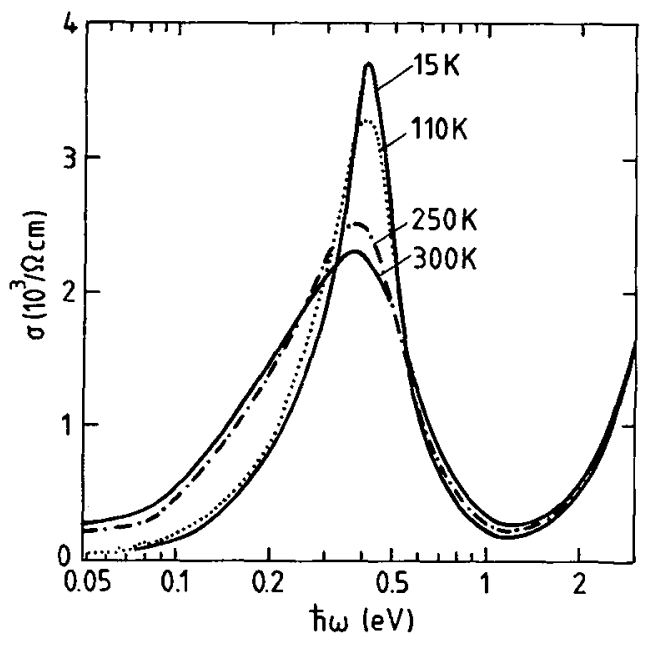

Fig. 4 - Longitudinal optical conductivity of $\left(\mathrm{TaSe}_{4}\right)_{2} \mathrm{I}$ at different temperatures.

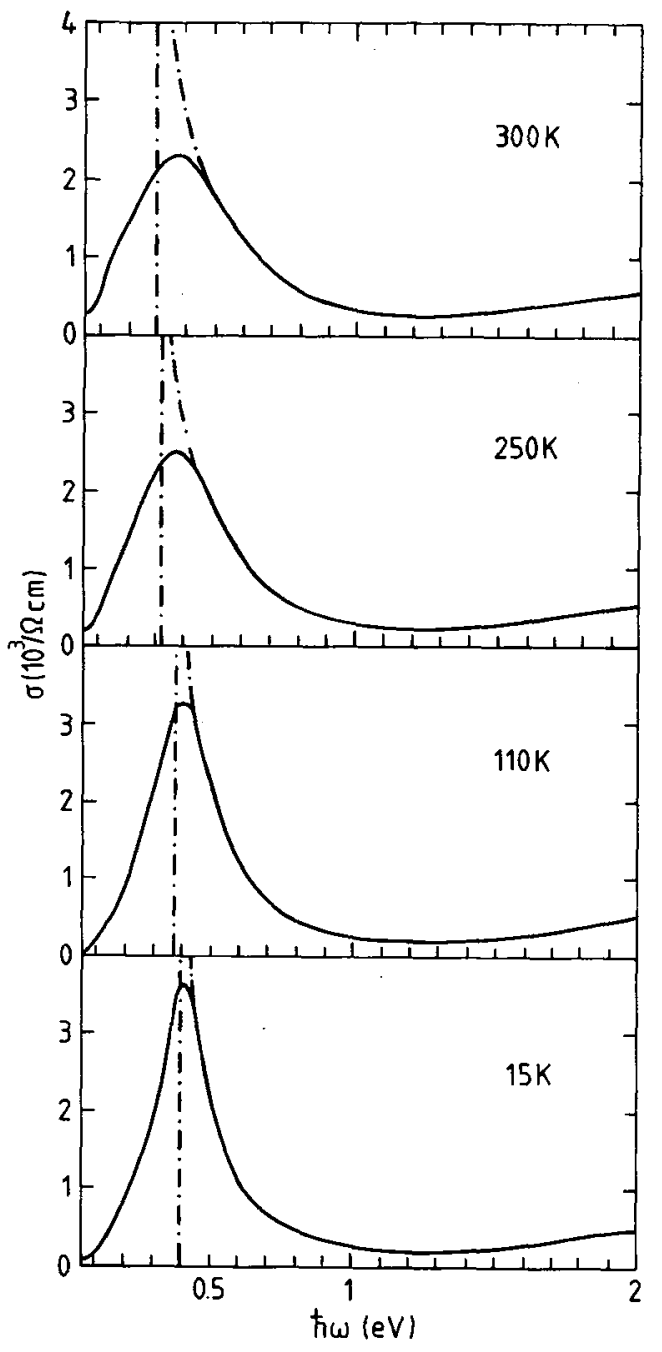

Fig.5 - Evolution of the Peierls gap of $\left(\mathrm{TaSe}_{4}\right)_{2} \mathrm{I}$ with decreasing temperature (full lines), compared with the joint density of states of a one-dimensional solid (dasheddotted lines). 
energy increases slightly. If we take the value of $400 \mathrm{meV}$ as the limit for $\mathrm{T}=0$ it follows from the relation

$$
2 \Delta=3.5 \mathrm{kT}^{\mathrm{MP}}
$$

a value of $\mathrm{T}^{\mathrm{MF}}=1370 \mathrm{~K}$ for the mean field transition temperature. This may be the temperature, where the free carriers condense to a charge density wave "liquid". At the transition temperature $\mathrm{T}_{\mathrm{p}}=263 \mathrm{~K}$ this charge density wave "liquid" crystallizes to a static charge density wave superstructure.

Acknowledgement

This work was supported by the Commission of the European Communities under contract no CI1-0526$\mathrm{M}(\mathrm{CD})$.

References

[1] see for a review: Monceau, P., in: Monceau, P., (ed.), Electronic Properties of Inorganic Quasi-One-Dimensional Materials, part II, p.139, D.Reidel 1985, and Grüner G., Rev. Mod. Phys. 60 (1988) 1129 and references therein.

[2] Roucau, C., Ayroles, R., Gressier, P. and Meerschaut, A., Solid State Comm. 46 (1983) 325.

[3] Fujishita, H., Sato, M., and Hoshino, S., Solid State Comm. 49 (1984) 313.

[4] Geserich, H.P., Scheiber, G., Dürrler, M., Lévy. F., and Monceau, P., Physica 143 B (1986) 198. 